\title{
A filosofia e sua possível contribuição educacional para pensar os desafios contemporâneos
}

\section{Philosophy and its possible educational contribution to think about contemporaneous challenges}

\author{
1 Sérgio Eduardo Fazanaro Vieira sfazanaro@gmail.com \\ 1 Presley Henrique Martins \\ 1 Leonardo Prates Brugnerotto
}

1 Pontifícia Universidade Católica de Campinas

\section{Resumo}

O presente estudo é oriundo do grupo de estudo e pesquisa sobre o ensino da Filosofia e seus fundamentos, da Faculdade de Filosofia da Pontifícia Universidade Católica de Campinas inserido no Programa Institucional de Bolsa de Iniciação à Docência. 0 objetivo central é discutir o papel da Educação como construção do ser humano e seus valores diante das atuais dificuldades no âmbito escolar e na prática de ensino, em decorrência das dinâmicas sociais hodiernas. Por meio da pesquisa bibliográfica, reflete-se sobre os elementos frágeis, quando se concebe a educação em suas propostas valorativas no processo educacional. Os teóricos escolhidos foram Werner Jaeger, Gilles Lipovetsky e Zygmunt Bauman. Retoma-se Jaeger sob o prisma de entender a sociedade e a cultura ocidental; Lipovetsky, pela concepção da era do vazio a partir das fragilidades nas atuais relações sociais; Bauman, ante à concepção de relações líquidas, aquelas que parecem perder o caráter de integralidade na formação humana; por fim, a partir de Gilles Deleuze e Félix Guattari, reflete-se o contexto contemporâneo sob o prisma do trabalho filosófico na criação de conceitos, conforme Renata Aspis e Sílvio Gallo em suas pesquisas sobre o ensino de filosofia para jovens do ensino médio. Como resultado, procura-se, além de possibilitar uma reflexão sobre os contornos da atual prática docente, fomentar o repertório de debates sobre os enfrentamentos que a Filosofia e seu ensino perpassam frente às atuais formas e objetivos das relações sociais.

\section{Palavras-chave:}

Filosofia. Educação. Ser humano.

\begin{abstract}
The present work comes from the group of study and research about the teaching of Philosophy and its bases, from the Philosophy College of the Pontifícia Universidade Católica of Campinas inserted in the Institutional Program of Scholarship for Initiation to Teaching. The central goal is to discuss the role of Education as construction of the human being and their values in the presence of current difficulties in the school scope and in the teaching practice because of modern social dynamics. By means of bibliographical research, one may think about fragile elements when education is conceived in its qualitative proposals in the educational process. The chosen theorists were Werner Jaeger, Gilles Lipovetsky and Zigmund Bauman. Jaeger is taken under the perspective of understanding the western Society and culture; Lipovetsky, for the conception of the era of emptiness from the fragilities in the present social relationships; Bauman, for the conception of fragile relationships, those which seem to lose their integrity in the human formation; finally, from Gilles Deleuze and Félix Guattari, one reflects about the contemporary context, under the view of philosophical work in the creation of concepts, as approached by Renata Aspis and Silvio Gallo in their research on the teaching of philosophy for young people in high school. As a result, besides making possible a contemplation of the contours of the present teaching practice, we seek to foment the debating repertoire about the challenges that Philosophy and its teaching pervade before the modern ways and goals of the social relationships.
\end{abstract}

\section{Keywords:}

Philosophy. Education. Human being.

\section{Como você deve citar?}

VIEIRA, Sérgio Eduardo Fazanaro; MARTINS, Presley Henrique; BRUGNEROTTO, Leonardo Prates. A filosofia e sua possível contribuição educacional para pensar os desafios contemporâneos. Cadernos UniFOA, Volta Redonda, n. 37 , p. 59-68, ago. 2018. 


\section{INTRODUÇÃO}

Desde os primeiros anseios para compreender a vida humana e suas formas de ser e estar no mundo, possivelmente o que se tenha almejado - como um projeto civilizatório, seria o homem como um ser de relação, que constrói seu espaço social, sua cultura e formas políticas de organização. Lançar esse olhar merece atenção diante de diligências que, mesmo de maneira limitada e contraditória, implicam uma unidade cultural a partir do espírito humano. Por aludir à existência humana, essa característica - unidade cultural - requer que se amplie ainda mais nosso olhar, nossa compreensão, o que implica abrir um leque de possibilidades complexas.

A complexidade em estabelecer quais parâmetros podem ou não construir o conceito 'humanidade' nos condiciona a uma escolha: buscar esse conceito no âmbito da educação e da cultura, posto que são elas que nos possibilitam compreender as teias sociais que se formaram ao longo da história humana, sobretudo aos desafios contemporâneos, intensos por crises e conflitos e que parece anunciar a necessidade de repensar o mundo plural e dinâmico.

Ao sentido atribuído que hoje emprega-se à ideia de educação e, principalmente, de cultura, vale considerar a contribuição decisiva dos gregos helênicos para aquilo que, depois, recebeu o nome de 'revolução cultural e formação do ocidente'. Na Grécia Clássica, o conceito de Paideia, em seu bojo, condiciona a formação do ser humano em sua integralidade e, ainda, fundamenta-se em uma visão de mundo que contribui com as necessidades das cidades-Estados através das ações do homem. Dessa forma, possibilita-nos compreender a cultura como um complexo de bens, mediante os quais o homem se apercebia sobre seu próprio valor e os fins a que deveria subordinar sua educação.

A educação é o princípio por meio do qual a comunidade humana conserva e transmite a sua peculiaridade física e espiritual. [...] conduz progressivamente à descoberta de si próprio e cria, pelo conhecimento do mundo exterior e interior, formas melhores de existência humana. [...] a educação participa na vida e no crescimento da sociedade, tanto no seu destino exterior como na sua estruturação interna e desenvolvimento espiritual; e, uma vez que o desenvolvimento social depende da consciência dos valores que regem a vida humana [...] (JAEGER, 2013, p.1-2)

De acordo com Jaeger, os homens eram educados sob a perspectiva de uma cosmovisão compreender o mundo, as relações humanas e os papéis dos indivíduos enquanto inseridos em dada sociedade. No transcorrer do tempo histórico, as formas e a presença dos elos formativos para o exercício das atividades humanas atendiam, evidentemente, as necessidades estabelecidas no seio social, porém, mudanças lentas e gradativas proporcionaram outros contornos, e novos comportamentos desdobraram-se na tentativa de atender ou suprimir os anseios dos indivíduos.

Atualmente, as relações humanas refletem as mudanças ocorridas nos mais de 25 séculos que nos separam dos helênicos. 0 mundo contemporâneo é permeado de transformações intensas, rápidas e complexas. Se antes os valores eram transmitidos e recebidos já definidos e aceitos, atualmente o homem elabora o próprio critério de valoração, produz em vez de memorizar conhecimento, abre novos horizontes em vez de se enquadrar no existente, estas, entre dezenas de outras formas de agir, julgar, assimilar, se assim o desejar.

Em meio a crises, conflitos, desigualdades, ou até perspectivas reduzidas, ele lida com o prisma do mundo que o cerca e concebe diversas interpretações, porém, muitas vezes, não se enquadra em modelos, ao contrário, sente-se solto na roda das relações, nas trocas sociais, nos frágeis laços com seus pares, como se levitasse - vazio - diante do mundo concreto. As tumultuadas transformações em que se vive parece exigir competências que estão distantes dos modelos políticos de Estado (educacional) para a viabilidade de um projeto que pense a formação humana em sua integralidade. A educação, sob esse prisma, deve ir além de aprender o pensamento linear, pois as questões e os desafios do mundo contemporâneo afetam diretamente as concepções educacionais na formação humana. A forma é múltipla, plural e em rede. 
Uma contribuição importante para pensar esse contexto é desenvolvida por Lipovetsky. Em suas considerações, interpreta o vazio que predomina no mundo contemporâneo: o homem como um ser deslocado da própria existência e que tenta preencher o vazio pelo engodo do consumo é um ser frustrado. Essa condição parece ser constante, pois a promessa é uma quimera. 0 efeito do consumo entorpece a infelicidade, e como qualquer entorpecente, quando não tiver mais o mesmo efeito, aumenta-se a dose, qual seja, o consumo.

Frenesi consumidor, mutilação da vida: no rastro traçado pela crítica marxista da religião, filósofos e sociólogos não deixaram de interpretar a propensão a comprar como um novo ópio do povo, destinado a compensar o tédio do trabalho fragmentado, as falhas da mobilidade social, a infelicidade da solidão. "Sofro, logo compro": quanto mais o indivíduo está isolado ou frustrado, mais busca consolos nas felicidades imediatas da mercadoria. Ersatz da verdadeira vida, o consumo exerce sua influência apenas na medida em que tem a capacidade de aturdir e de adormecer, de oferecer-se como paliativo aos desejos frustrados do homem moderno. (LIPOVETSKY, 2007, p.37)

Esse homem é o reflexo da sociedade de hiperconsumo e dos valores que são transmitidos por essa mesma sociedade. Nesse sentido, entendendo por valor aquilo que a pessoa tem como primazia na vida e que é o norte de suas escolhas, os valores são diversos e complexos. Ainda, Lipovetsky entende que, no presente momento,

nasce toda uma cultura hedonista e psicologista que incita à satisfação imediata das necessidades, estimula a urgência dos prazeres, enaltece o florescimento pessoal, coloca no pedestal o paraíso do bem-estar, do conforto e do lazer. [...] políticas do futuro radiante foram sucedidas pelo consumo como promessa de um futuro eufórico. (LIPOVETSKY, 2004, p. 61)

Diante dessa perspectiva, as relações dos indivíduos apresentam uma não formidade, já que se configuram também de forma líquida, pois encontram-se engajados em um mundo de trocas e mudanças, com novos paradigmas em curto espaço de tempo. Com isso, as sólidas comunidades estão desaparecendo e as pessoas passam a conviver em rede, onde as facilidades de conexão e desconexão exponenciam sua grande fragilidade. (BAUMAN, 2001).

Ao apontarmos para os elementos que nos provoca pensar a educação do homem contemporâneo, parece-nos necessário eleger a filosofia como ferramenta de produção de discernimento que, além de contribuir com o pensar, com as ações e atitudes, pode também compreender as condições histórico-sociais que engendram a atual materialidade existencial.

Diante desses prismas, é necessário se debruçar sobre a questão: como construir, atualmente, uma educação que tenha em seu bojo o ser humano? Para evitar anacronismos conceituais, investiga-se a formação do indivíduo alicerçada em panoramas histórico-filosóficos que possibilitam a chave para pensar as questões emergentes em meio a aspirações diferentes, aptidões e contornos sociais não equivalentes. $O$ âmago a ser analisado é que as transformações sociais acompanham uma série de questões humanas, das quais essa formação - de um único lugar - a escola pode desconsiderar uma proposta de educação que atenda às necessidades de cada um.

O tema que se apresenta, a construção do ser humano e seus valores, possui referencial teórico abrangente. Para este artigo, escolheu-se apresentar algumas ideias de Jaeger, Lipovetsky e Bauman, para pensar os desafios do contexto contemporâneo e a contribuição que o ensino de filosofia poderá oferecer, discutidos pelos pesquisadores sobre o tema, Aspis e Gallo.

\section{CONSIDERAÇÕES SOBRE A CONSTRUÇÃO DO SER HUMANO E SEUS VALORES}

Diante da dinâmica social ágil, frágil e em constante mudança e evolução, o filósofo francês Gilles Lipovetsky tem sido apontado como pensador abalizado como crítico do atual comportamento social e da ânsia de consumo como fator compensatório do vazio humano. Ele conceitua a hipermodernidade - que tem 
em seu bojo os novos conceitos, o hiperconsumo e o hipernarcisismo. Em seu livro, "Felicidade paradoxal" (2007), destaca a 'revolução copernicana' na indústria, que é a passagem da centralidade do produto à procura por ele. Para o autor, a durabilidade dos produtos está proporcionalmente ligada à procura efervescente, o que acelera a busca por inovação e diminui o tempo de uso de um determinado produto. Seguindo essa lógica, o produto passa por um processo que se orienta por um sistema de fidelização voltado ao consumidor e ao mercado. Na sociedade do hiperconsumo, como aponta o autor, a febre do conforto substitui o lazer, o que se vende não é produto, mas a promessa de satisfação que esse produto oferece; esse 'produto' atende a uma necessidade criada no imaginário do ser humano, que é reduzido pelo mercado como "Homo Consumericus".

Um Homo-consumericus de terceiro tipo vem a luz, uma espécie de turbo-consumidor desajustado, instável e flexível, amplamente liberto das antigas culturas de classe, imprevisível em seus gostos e em suas compras. De um consumidor sujeito as coerções sociais da posição, passou se a um hiperconsumidor à espreita de experiências emocionais e de maior bem-estar, de qualidade de vida e de saúde, de marcas e de autenticidade, de imediatismo e de comunicação. (LIPOVETSKY, 2007, p.9)

A satisfação se confunde com a felicidade no imaginário desse consumidor, emergindo um sentimento de necessidade de sempre estar consumindo para se adequar às inovações lançadas no mercado; esse produto tem sua validade diminuída para que gere novas necessidades de compra para a manutenção da 'felicidade'. Assim, a nova era do capitalismo se constrói em torno do consumidor, que predomina nesse sistema; a felicidade é tão efêmera quanto o produto e a mercantilização invade todas as experiências em todo lugar, deixando o homem acorrentado a uma felicidade paradoxal que gera satisfação à medida que gera insatisfação. Essa mercantilização das experiências causa uma individualização, alavanca a competição pela aquisição de bens e a felicidade se torna objeto de conquista. Nessa corrida desenfreada, segundo o pensador, o troféu se restringe ao grupo, deixando para trás um grande envolto de fumaça que esconde a escória invisível. 0 aumento da riqueza também gerou um número crescente de precariedade, falta de dinheiro e uma preocupação cada vez mais obsessiva, gerada por elas (LIPOVETSKY, 2007). Essa preocupação leva o homem a se antecipar, buscando se profissionalizar, mantendo-se atualizado para permanecer no mercado e no consumo. Como resultado, temos um aumento de insatisfações, decepções, e insegurança quanto ao futuro incerto que o assola, e que confere aspectos inextricáveis na sociedade do hiperconsumo e da felicidade paradoxal.

\footnotetext{
Daí a condição profundamente paradoxal do hiperconsumidor. De um lado, este afirma como um "consumidor", informado e "livre", que vê seu leque de escolhas ampliar-se, que consulta portais e compradores de custo, aproveita as pechinchas do low-cost, age procurando otimizar a relação qualidade/preço. Do outro, os modos de vida, os prazeres e os gostos mostram-se cada vez mais sob a dependência do sistema mercantil. (LIPOVETSKY, 2007, p.10)
}

Com Zygmunt Bauman, sociólogo polonês, se quisermos entender a estrutura da modernidade, para falar da educação, será necessário investigar mais as características fundamentais dela. Se a modernidade é chamada de vazia e efêmera por Lipovetsky, Bauman a chama de líquida, e umas das principais características dessa liquidez é a sua fluidez; os líquidos são incapazes de oferecer qualquer resistência, quando submetidos a algum tipo de stress, contornam os possíveis moldes que tentam reter sua forma; as estruturas sólidas do passado foram derretidas, com o intuito de estabelecer novos sólidos duradouros, mas falharam e se liquefizeram; as instituições, que antes regiam o homem, não estão mais à mesa; depois da liquefação das grandes instituições, o que houve foi uma distribuição da liquidez e agora ela perpassa todas as esferas da sociedade, as instituições, os trabalhos, moradias, bens e até as relações se tornam líquidas (BAUMAN, 2001).

Atribuindo a esse contexto o conceito de Modernidade líquida, temos como resultado uma sociedade que tem como características a individualização, o deslocamento do indivíduo em relação ao todo, que envolve a fragilidade das relações humanas, que se associa com a facilidade de se conectar e desconectar sem prejuízo. Essa percepção nos auxilia a entender as relações pelas quais atravessam essa sociedade 
em que estamos intimamente ligados. 0 termo conectar-se ou desconectar-se advém da ideia de rede, que está em oposição à ideia de comunidade, que envolve parentescos, parceria mútua, e exclui o seu oposto, a falta de compromisso e aqueles estranhos a ela. Nós pertencemos à comunidade, que exerce poder sobre nós, pode regular nosso comportamento e dizer se nos aceita ou não. Enquanto a rede, por sua vez, nos pertence, nós fazemos a rede e ela resistirá enquanto nossos interesses a ela estiverem direcionados. Conectar-se e desconectar-se permanecem como duas possibilidades que não se anulam, já que a conexão é muito mais atrativa, pois não envolve o compromisso e a responsabilidade, e a febre por liberdade, que gera uma facilidade da afırmação do "eu" em detrimento de nós.

Constata-se que as relações na modernidade líquida estão fundamentadas na noção de rede e podem ser interrompidas a qualquer momento, pois se abre a possibilidade de encontrar o que for mais satisfatório e completo; essas possibilidades crescem exponencialmente, a fluidez então se torna o meio para encontrar essa completude, que se potencializa à medida em que se realiza, irrompendo a ilusão de que a relação posterior irá superar a relação anterior. Essa incessante busca acontece porque no rompimento não há dor, nem sofrimento, porque na lógica da conexão não há raízes profundas que estabeleçam a ligação com o outro, ao contrário, nas relações líquidas um é estranho ao outro. Cada um se comunica consigo mesmo, não há uma interação, a fragmentação faz com que o indivíduo consiga ver somente suas próprias vontades. "Ainda há um grande abismo entre a condição de indivíduos de jure e indivíduos de facto - isto é, de ganhar controle do próprio destino e tomar as decisões que verdadeiramente desejam" (BAUMAN, 2003, p. 53).

Considerando a educação e as demandas do homem contemporâneo, parece interessante retomar a ideia de Jaeger, sem anacronismo, mas percebendo o contexto do mundo grego em que o conceito 'paideia' foi pensado: os gregos foram os que, pela primeira vez no ocidente, colocaram a educação e todo seu conjunto de valores e formas de acontecer como problema. Para os gregos, toda civilização que atinge certo grau de desenvolvimento transmite, através da educação, os valores que são preservados pelo costume. Paideia significa criação das crianças, mas acima de tudo: formação ou "[...] a forma primeira, original e originária, do ideal educativo grego" (FONSECA, 1998, p. 2). Essa concepção de educação contempla toda a cultura em que ela, a educação, tem por finalidade última - o ser, e está relacionada com a atuação na vida e no crescimento da sociedade. Há presente no mundo contemporâneo, por suas inúmeras demandas, um enfraquecimento ou até mesmo um ignorar o que parecer ser mais importante, quando se pensa modelos e projetos educacionais: a formação humanística. Eis o desafio!

\section{A CONTRIBUIÇÃO DA FILOSOFIA PARA PENSAR A FORMAÇÃO HUMANA DIANTE OS DESAFIOS CONTEMPORÂNEOS}

Ao se deparar com o contexto atual, tendo como horizonte as perspectivas de Lipovetsky e Bauman, e refletindo sobre o papel que a educação tem para sociedade, precisamos nos perguntar: Como construir, atualmente, uma educação que tenha em seu bojo o ser humano? Pois, parece que a educação está vinculada com a visão de mundo que se reflete na estrutura socioeconômica. Nesse sentido, com o encantamento sobre o mundo reduzido à exploração, solapou-se a posição do ser humano, surtindo efeito em seu processo formativo, assim se preconizou a formação do Homo-consumericus, o homem que atende as necessidades do mercado e que, por isso, esquece-se da formação integral do ser humano, deixando-o preso aos parâmetros estabelecidos pelo mercado.

Libertar-se significa soltar-se de algum tipo de impedimento, sentir-se livre para se mover ou agir. Sentir-se livre quer dizer não experimentar dificuldades ou obstáculos para os movimentos pretendidos. Sentimo-nos livres na medida em que atendemos aos nossos desejos. Assim, a liberdade pode ser mantida de duas formas: ou diminuindo os desejos ou ampliando a sua capacidade de ação (BAUMAN, 2001). 
Entretanto, prolifera a concepção de que as noções de liberdade e desejo estão intimamente ligadas. Pois, se com liberdade pretendemos dizer que ela presume a remoção de dificuldades para a nossa ação, então temos nossa liberdade na mesma medida em que atendemos aos nossos desejos. A sensação de ser livre é a sensação de atender aos desejos que são criados no imaginário do ser humano.

Posto isto, a ação deve corresponder a capacidade que não esteja vinculado ao desejo frívolo produzido pelo mercado. Essa concepção cerceia as possibilidades humanas e o encarcera na circularidade desejo-consumo. Voltando nosso olhar para o âmbito escolar, quando se observa a grade de disciplinas do ensino médio, nota-se que há o predomínio de competências que são consideradas úteis para o trabalho, para futuras profissões, ou seja, as disciplinas apresentam-se conteudistas, com mera transmissão de conhecimentos que devem ser reproduzidos na lógica da utilidade.

À margem das competências, encontra-se a Filosofia, que corre o risco, diante de uma política de Estado, de reproduzir apenas conteúdos em cumprimento do currículo ou até mesmo atendendo as demandas avaliativas, por exemplo, as de larga escala. A lógica da utilidade é marginalizada e, muitas vezes, não vivenciada de maneira significativa por estudantes e, ainda, por professores que "repetem o mesmo".

Essa é a situação em que estamos: o valor transmitido no processo de formação na contemporaneidade é o da utilidade, que visa o conforto material, pois, desde que se está inserido na escola, esquece-se o humano, que é inundado desde o começo com disciplinas práticas, consideradas essenciais para a profissionalização e o exercício dela no mundo voltado para o consumo. As escolhas das profissões são norteadas para aquilo que é mais rentável ou útil no âmbito do mercado.

Se considerado a especificidade do saber filosófico e o comprometimento da mediação realizada para propiciar os caminhos desse saber, poderemos estabelecer um caminho que minimamente faça sentido aos jovens do ensino médio. Para isso, torna-se necessário pensar estratégias que possibilitem o voltar-se ao humano, questionar e questionar-se, movimentando o pensamento e o sentido do existir. 0 ensino filosófico não se delimita como disciplina, pois é uma prática constante do espírito humano.

A potencialidade que possui o ensino de filosofia deve ser a mola propulsora da atividade docente que, muitas vezes, inserida nas relações de rede, pode desanimar, se depararem-se com uma sala de aula com alunos desinteressados. Por sua vez, os discentes, que logo engendram-se na teia da hipermodernidade, foram formados para se preocuparem com seus problemas que, geralmente, estão atrelados com a satisfação do imaginário pelo consumo.

Embora o ambiente escolar possa, em certa medida, parecer inóspito, não deve haver recuo diante desses impasses, pois a responsabilidade está a cargo dos docentes, que devem fazer com que o ensino não seja tratado de maneira displicente, mas sim, com a reflexão a partir de problemas concretos e singulares sobre as particularidades e as diferenças que compõem a pluralidade de uma sala de aula.

Para os filósofos franceses Gilles Deleuze, e Félix Guattari, a especificidade da Filosofia é o conceito filosófico. A Filosofia, assim como a arte e a ciência, é potência criativa do pensamento, mas com a especificidade em pensar por meio de seus próprios conceitos. A pesquisadora da área Renata Aspis compreende que

Filosofia é criação. Filosofia é experiência de pensamento. Filosofia é experiência de pensamento a partir de problemas. O problema move o pensamento. As construções das filosofias são, necessariamente, buscas de equacionar problemas. Problemas são incômodos. Problemas trazem impossibilidades que precisam ser transpostas, eles plantam a necessidade de criação de saídas. Problemas afetam, obrigam, empurram. (ASPIS, 2012, p. 92) 
Filosofia pode ser busca de conhecimento das essências, método de se chegar à verdade; dependendo da filosofia, pode ser pensamento autônomo, pode ser reflexão, crítica; filosofia pode ser criação de conceitos. Todo conceito tem sua história, que não tem o caráter informativo, já que a informação imprime a ideia de se acreditar em uma crença; a informação é utilizada pela sociedade do controle e esta que nos controla por meio das informações que comunicam aquilo em que devemos acreditar, conhecer, julgar ou não. Essas informações, que condicionam crenças, são fornecidas desde a infância, incluindo o período do processo escolar; a informação cria o imaginário de satisfação e o associa à necessidade do consumo.

O conceito filosófico, ao contrário, não informa, mas nos fala, e essa fala é disjuntiva, pois aquilo que é falado nos faz ver outra coisa criando outras possibilidades. 0 conceito filosófico se traduz como resistência, pois resiste aos limites do tempo e da morte, por isso os filósofos que já se debruçaram nos mais variados problemas da vida ainda nos falam através de conceitos. 0 conceito é um ato do devir que possibilita uma ressignificação. Assim, a Filosofia é um ato de discernimento e de resistência, pois abrange uma dimensão criativa do pensamento. Daí a importância, para o contexto do ensino médio, da mediação docente que poderá possibilitar a experiência da criação de conceitos, o que não é uma tarefa fácil.

Para Sílvio Gallo (2007), pesquisador sobre o ensino de Filosofia, é possível que os conceitos já presentes na história da filosofia sejam trabalhados de modo a realizar a experiência do pensamento, fazendo com que alunos façam a ressignificação ou até mesmo criem seus próprios conceitos, de maneira que esses conceitos respondam aos problemas dos quais enfrentam na vida. 0 autor afirma que

ora, nossos currículos de ensino médio são absolutamente científicos. Na mesma medida em que possibilitam o
exercício dessa potência (quando o possibilitam, pois na maioria das vezes temos um ensino instrumentalizado
e conteudista da ciência), acabam por desprezar as potências da arte e da filosofia. Penso que esta seja uma
justificativa pertinente para a presença da filosofia nos currículos da educação média: a busca de um equilíbrio
entre as potências da arte, da ciência, da filosofia, de modo que os jovens possam ter acesso a estas várias
possibilidades de exercício do pensamento criativo, aprendendo a pensar por funções (ciência), mas também
por perceptos e afectos (arte) e por conceitos (filosofia). Daí a importância da presença da filosofia no ensino
médio: ela se constitui numa experiência singular de pensamento, e se o estudante não se encontrar com ela
nesse nível mais abrangente de ensino, pode ser que jamais o faça. Penso ser essa uma justificativa mais que
suficiente. (GALLO, 2007, p. 22)

Essa ressignificação do conceito parte da problemática das situações em que se encontram os estudantes de Filosofia, ao invés do ensino a partir de uma igualdade ilusória, ao contrário, inicia nas diferenças de cada um, permitindo um momento de contenção da liquidez que propõe que cada indivíduo reflita sobre os valores que estão sendo construídos como sujeitos que compõem uma mesma sociedade. A sensibilização quanto aos problemas rompe com as barreiras impostas pelas aparências que os envolvem, fazendo com que criem seus próprios conceitos com a finalidade de encontrar outras possibilidades de vida, sendo esse encontro um ato de resistência.

A partir da noção de conceito posta por Deleuze e Guattari, a filosofia não é apenas um conjunto de conheci-
mentos criados historicamente, mas sobretudo uma atividade criativa, na medida em que o filósofo, encarnado
e vivendo num mundo concreto, enfrenta problemas vitais, mergulha no caos e busca a criatividade que lhe
permita inventar conceitos que ajudem a dar uma forma racional ao problema vivido, podendo assim encontrar
soluções. (GALLO, 2006, p.24)

No entanto, a Filosofia não se encerra como disciplina no período escolar. Ela acompanha toda a existência em suas diversas etapas e tem sua utilidade para outra esfera da vida, diferente da utilidade prática sustentada pelo poder aquisitivo. Ao se encontrar com um mundo hostil, cujos valores estão ancorados na modernidade líquida e do hiperconsumo, as intempestividades se manifestam como devastadoras. Os valores contemplados pela formação do Homo-consumericus não ensinam o homem a lidar com as difíceis e frágeis fases que também fazem parte da vida, das quais todas as pessoas estão fadadas a passar. Ao invés disso, fazem com que o homem se veja sobre um abismo consumido de incertezas, no vazio que já o consumia enquanto se enredava nas promessas embusteiras de felicidade. 
Cabe aqui lembrar do filósofo Boécio, que viveu no séc. VI d.C.. Quando estava preso e condenado à morte, escreveu a obra "Consolações da filosofia", no momento mais difícil de sua vida. Ele invocou a filosofia para Ihe mostrar o verdadeiro valor da vida, fazendo-o perceber aquilo que realmente importava, ao mesmo tempo que vislumbrava um significado de existência profundo e acalentador, e descobriu a verdadeira felicidade que perpassa todo o sofrimento, resistindo, dessa forma, aos problemas vitais pelo qual passava.

Portanto, a Filosofia foi a morada de Boécio, quando se viu em uma situação de extrema dificuldade. Assim, a Filosofia pode proporcionar a reflexão necessária, quando os ventos da fortuna estiverem contra, fazendo com que o conceito revele um mundo novo, cuja vida encontra outras possibilidades, e que, pela resistência, encontra sua liberdade para novas formas de vida.

A Filosofia cumpre o papel de se despir das ilusões da sociedade contemporânea, apercebendo-se as situações diversas e fazendo revigorar o autoconhecimento para o enfrentamento das nocividades da hipermodernidade. Depende essencialmente que o docente crie condições para que o ensino da Filosofia e o filosofar sejam produtivos, expondo os conceitos e propondo a ressignificação deles, partindo da realidade e das situações das quais seus alunos fazem parte. A filosofia preservou, no decorrer dos séculos, a faculdade de pensar o sentido da vida humana, podendo recuperar a ideia de uma educação que se volte para sua condição de cultura, e busque nela o intrínseco valor do ser humano.

O ensino de Filosofia contempla a potência criativa do conceito e, consequentemente, realiza um papel formador para o pensar. Este, por sua vez, busca responder aos problemas concretos os quais abordamos, de uma sociedade formada para o consumo. Ao realizar a experiência do pensamento conceitual, os alunos podem questionar e buscar solução para os próprios problemas vividos no contexto do vazio que predomina na sociedade do hiperconsumo, fazendo com que percebam que existem outras possibilidades de vida e não somente o da utilidade puramente instrumental baseada na produtividade do capital. Dessa forma, o ensino de Filosofia, além de necessário no âmbito escolar, possibilita que sejamos criativos e livres para enfrentarmos os desafios contemporâneos de uma sociedade cada vez mais vazia e encarcerada em uma única forma de vida - consumir.

\section{CONSIDERAÇÕES FINAIS}

No atual contexto em que vivemos, mostra-se necessária a reflexão sobre a educação. Além das dificuldades que encontramos no ensino, estamos em uma sociedade individualizada, que se baseia em preocupações frívolas, sendo que é a educação a propulsora da formação da pessoa humana - ela é a base na qual deve ser pensada e trabalhada a mudança que queremos ver no mundo. Evidencia-se o quão necessário é analisar o que está no âmago dessa formação, compreendendo as questões emergentes, os valores presentes e seus fins.

Por meios dos teóricos apresentados neste artigo, buscou-se parâmetros diversos para estabelecer uma análise sobre a complexidade do homem contemporâneo e os desafios que perpassam os processos educacionais e a formação do ser humano. Mediante os conceitos analisados, perscrutou-se, na contemporaneidade, os valores nos quais a educação está ancorada. Dessa forma, expandiu-se a reflexão para uma abordagem crítica sobre os problemas hodiernos na esfera social e educacional. Através das análises propiciadas pelos autores Bauman, Lipovetsky e Jaeger, e na comparação com as situações contemporâneas, podemos ressaltar que, diferentemente de uma formação, temos uma educação voltada para o mercado e para o consumo, que prepara somente para se exercer uma atividade remunerada e não busca a formação para o enfrentamento das adversidades da vida. 
Sendo a educação um veículo que imprime valores e costumes de uma sociedade, podemos inferir que a atual não considera outros âmbitos da vida humana, reduzindo a prática individual, que busca uma satisfação hedonista e efêmera, pois a formação consiste somente em realizar uma necessidade do mercado, tornando, dessa forma, nossas experiências mercantilizadas e dependentes dela. Por outro lado, Aspis e Gallo apresentam a ideia de uma "pedagogia do conceito", capaz de oferecer um exercício de resistência à opinião e aos tempos hipermodernos na atividade filosófica, presente na obra de Deleuze e Guatarri. Essa prática pedagógica incita ao ensino da filosofia uma atividade do pensar como ato criativo de um conceito, que pode contribuir de maneira responsável, pensando sobre o homem integral e suas formas de vida.

A Filosofia possibilita a reflexão e a percepção sobre esses problemas estruturais, fazendo com que o ser humano busque valores que estejam em harmonia com o seu interior e exterior. Nas relações entre docentes e discentes, há uma relação de rede que se mostra na facilidade de conectar e desconectar, mostrando uma indiferença que já está pressuposta na prática de ensino que não considera as diferenças, isto é, caracterizando, porque ambos (docentes, discentes) são produtos da hipermodernidade e da modernidade líquida. A filosofia, em defesa de seu ensino, mostra-se fundamental por proporcionar a liberdade de reflexão, de agir no e com esse mundo delineado historicamente sob os horizontes de possibilidades e indistinções.

A potência específica em lidar com concepções conceituais refina a capacidade dos discentes para se munirem de condições cada vez mais apuradas linguisticamente e, portanto, deslocadas das redes de significantes-significados medíocres. 0 ensino de Filosofia tem a oportunidade, assim, de sair do ciclo das disciplinas de valores de conformação, dando lugar aos valores de formação para o discernimento.

Assim, em defesa da tarefa que compete o saber filosófico e sua possibilidade de provocar o pensamento para suas próprias questões, a desconsideração como conhecimento, a diluição ou desmerecimento da Filosofia por via de medidas (ou até mesmo manobras) políticas, com interesses à não formação do homem em sua integralidade, torna-se um afronte à sua dignidade, a seu direito, e sobretudo, à condição de ser ciência em prol do ser humano. Uma educação filosófica coloca o momento da formação humana como acontecimento. Nele, se faz o pensar. Desconstruir o dado, o certo e o futuro ingênuo é compreender que o ensino de filosofia, quando de maneira responsável é vivenciado, torna-se elemento fundamental para uma educação humanística que pressuponha o homem integral, que pensa sua prática e seu mundo, capaz de pensar criticamente diante a complexidade que é o existir. 


\section{REFERÊNCIAS}

ASPÍS, R. Ensino de filosofia e resistência. Tese de Doutorado. Faculdade de Educação. Campinas, SP. Unicamp, 2012.

BAUMAN, Zygmunt. Modernidade líquida. Rio de Janeiro: Zahar, 2001.

Amor líquido. Rio de Janeiro: Zahar, 2004.

BOECIO, Anício M. T. Severino. A consolação da filosofia. 4. ed. São Paulo: Martins Fontes, 2016.

DELEUZE, Gilles. 0 que é a filosofia? 3. ed. São Paulo: Editora 34, 2010.

GALLO, Sílvio. A filosofia e seu ensino: conceito e transversalidade. In: SILVEIRA, R.; GOTO, R. Filosofia no ensino médio: temas, problemas e propostas. São Paulo: Edições Loyola, 2007.

FONSECA, Maria de Jesus. A Paideia grega revisitada. São Paulo: Millenium. 1998.

JAEGER, Werner. Paideia a formação do homem grego. 6. ed. São Paulo: Zahar, 2013.

LIPOVETSKY, Gilles. A felicidade paradoxal. São Paulo: Companhia das letras, 2007.

Os tempos hipermodernos. São Paulo: Barcarolla, 2004. 